\title{
Studies on Interaction of Lidocaine Drug with Natural Cellulosic Fibres
}

\author{
Md. Ashaduzzaman ${ }^{1, *}$, Abdullah Al-Rafin ${ }^{1}$, Nusrat Mustary ${ }^{2}$, \\ Sayed Md. Shamsuddin ${ }^{1}$ \\ ${ }^{1}$ Department of Applied Chemistry and Chemical Engineering, Faculty of Engineering and \\ Technology, University of Dhaka, Dhaka 1000, Bangladesh \\ ${ }^{2}$ Department of Community medicine, National Institute of Preventive and Social Medicine \\ (NIPSOM), Faculty of Preventive and Social Medicine, Bangabandhu Sheikh Mujib Medical \\ University, Dhaka-1000 \\ ${ }^{*}$ Corresponding author: E-mail: azaman01@du.ac.bd
}

Keywords: Adsorption, absorption spectroscopy, desorption, drug interaction, self-assembly

\begin{abstract}
Naturally engineered cellulosic fibres are of particular interest due to their diverse interfacial behavior; which could be well suited to operating interaction with functionalized drug. In the present work, interaction of Lidocaine (LC) hydrochloride, 2-(diethylamino)- $N-(2,6-$ dimethylphenyl)acetamide was widely studied with cellulosic fibres i.e. cotton, jute and coir in presence of $0.1 \mathrm{M} \mathrm{HCl}$ aqueous solution. In UV-Vis spectroscopy measurement, it is revealed that the highest interaction (adsorption $18 \mathrm{mg} / \mathrm{g}$ of fibres) of LC was occurred onto the cotton fibres surfaces from $3.5 \mathrm{mg} / \mathrm{mL}$ aqueous solution after 30 minutes gentle shaking. Kinetic studies in case of cotton fibres showed a linear relationship $\left(\mathrm{R}^{2}=0.9987\right)$ during desorption of LC upto 30 minutes at $25{ }^{\circ} \mathrm{C}$ temperature. The cotton fibres concentration was to be calculated $0.0085 \mathrm{~g}$ unit $\mathrm{mol} / \mathrm{L}$ by considering the unit molecular weight of glucose unit. When $2.5 \mathrm{mg} / \mathrm{mL}(0.0108 \mathrm{~g} \mathrm{~mol} / \mathrm{L}) \mathrm{LC}$ drug solution was used then the ratio between glucose unit and LC drug was found to be 1.27. The interaction of LC was also increased direct-proportionally to the weight of cotton fibres. The resulting interaction phenomena of model LC would help us to deign dosage of anesthetic drug for specific physiological conditions.
\end{abstract}

\section{Introduction}

Cellulose is one of the most widespread biopolymer found globally, existing in a variety of living species such as plant, animals, bacteria and some amoebas [1]. Natural fibers mainly consist of cellulose, lignin, and hemicellulose but also include low quantities of pectin, pigments and extracts. Cellulose chains are bio-synthesized by enzymes, deposited in a continuous organized fashion and aggregated to form microfibrils. The microfibrils further aggregate on the macroscale to form fibers. The natural fibers themselves act as composite materials, assembling in a mainly lignin matrix [2]. The cellulose content differs for different plant species. Cotton has the highest content of cellulose (90 99\%). Wood (40 50\%), jute $(60 \sim 70 \%)$ and flax fibers $(\sim 80 \%)$ are all main sources of cellulose [3]. Because of the large availability of cellulose, it has always been an important material in the life of humans. Because of the chemical nature, cellulosic surface bears numerous hydroxyl functions which give rise to highly active particles and can be used for drug delivery, sorption agents, coating, and membranes [4-6], through modification, adsorption-desorption/interaction mechanism.

Among the cellulose varieties, only microcrystalline cellulose (MCC) has been chosen as an excipient in pharmaceutical formulation for many years. Although MCC has been widely used in the field of drug formulations, not so many studies have been undertaken to clarify the interaction of drugs with MCC $[7,8]$. The fact is that the interaction type may depend to a certain extent on the properties of the components, method of activation and other factors [9-12]. There are few drugs, e.g. ketotifen [13], ampicilline and amoxycilline [14], fluphenazine dihydrochloride and promehazine hydrochloride [15] have been investigated to find out the adsorption capacity of MCC.

The application of purified and polished cotton fibres as DNA-streptavidin tags for bioapplications was reported by D. N. T. Kumar, et al. [16]. On the other hand, the possibility to use 
cotton as a matrix for controlled release systems of the reactive dye Remazol Brilliant Blue $\mathrm{R}$ and Methylene Blue as the model of drugs to its surface were reported by. A. C. Paulo et. al. [17] and A. R. Khan, et al. [18] respectively. Specific surface area of cotton fibres was measured using Methylene Blue dye by K. C. Kaewprasit and was found in the range of $30 \times 10^{-3}$ and $53 \times 10^{-3} \mathrm{~km}^{2} / \mathrm{kg}$. Some studies have indicated that adsorption increases when $\mathrm{pH}$ of the solution increases. [13-15, 20] This is attributed to the reduction of the solubility of the drug with the increase in $\mathrm{pH}$ [13]. Franz and Peck suggested [15] that it is due to the ionization of carboxyl groups on the cellulose surface. When the $\mathrm{pH}$ values of the suspensions are increased, the number of negatively charged carboxylate groups on the surface of the MCC particles increases. The increased number of anionic surface sites leads to increased adsorption of predominantly positively charged drugs at surface of particles. Franz and Peck also suggested that the possibility also excist that these hydrophobic drugs are adsorbed from solution as the nonprotonated free bases [15].

In this study an anesthetic drug, LC was used as an adsorbate and natural fibres (cotton, jute and coir) were used as the support for a potential application into a drug release system. To provide evidence of the concept, the drug was adhered by physio-adsorption to the fibre. The acidic water environment was used as the "switch on" agent to release the drug. The mechanism for the release of the drug proceeds via the erosion and swelling of the substrate (cellulose) with the concomitant release of the adsorbed drug.

\section{Experimental}

\section{Materials and methods}

Cotton fibres was purchased from Sumaya absorbent cotton wool, jute fibres and coir fibres were collected from local sources. Equivalent weight of cotton was measured from cotton bud obtained from local source. Lidocaine (LC) hydrochloride monohydrate (Mw 288.81, assay: >99\%) was purchased from Sigma-Aldrich and was used as received. Hydrochloric acid $(\mathrm{HCl}, 36.5 \%$, sp, gra. 1.18) was purchased from Merck India. Laboratory extracted starch (from local potato) was used as a viscosity enhancer. Distilled water was available in the lab. Glass apparatus $(10 \mathrm{~mL}$ volumetric flask, $100 \mathrm{~mL}$ volumetric flask and $100 \mathrm{~mL}$ beaker) were purchased from local market.

\section{Preparation of $0.1 \mathrm{M} \mathrm{HCl}$ aqueous solution}

In a $1 \mathrm{~L}$ volumetric flask, $8.7 \mathrm{~mL}$ concentrated $\mathrm{HCl}(36.5 \%$, sp, gra. 1.18$)$ was added with $700 \mathrm{~mL}$ distilled water and then make up water was added up to the mark.

\section{Preparation of standard LC aqueous solution}

LC hydrochloride monohydrate (18.5.mg) was dissolved in $500 \mathrm{~mL}$ of $0.1 \mathrm{M} \mathrm{HCl}$ to prepare $30 \mu \mathrm{g}$ $\mathrm{LC} / \mathrm{mL}$ aqueous solution. Then $30 \mu \mathrm{g} \mathrm{LC} / \mathrm{mL}$ solution was gradually diluted with $0.1 \mathrm{M} \mathrm{HCl}$ aqueous solution to produce a series of solutions $(25 \mu \mathrm{g} / \mathrm{mL}, 20 \mu \mathrm{g} / \mathrm{mL}, 15 \mu \mathrm{g} / \mathrm{mL}, 10 \mu \mathrm{g} / \mathrm{mL}$, $5 \mu \mathrm{g} / \mathrm{mL}$ ) and UV-Vis spectra were recorded within 200 to $800 \mathrm{~nm}$. Maxima were found at $262.5 \mathrm{~nm}$ with a slight variation between $262-263 \mathrm{~nm}$.

\section{Measurement of saturation time}

Cotton fibres as a model, $60 \mathrm{mg}$ was immersed into $50 \mathrm{~mL}$ aqueous solution of $0.1 \mathrm{M} \mathrm{HCl}$ containing $2.5 \mathrm{mg} / \mathrm{mL}$ of LC and stirred gently for 2, 3, 4, 5, 10, 15, 20 minutes separately. Then the cotton was collected and subjected to dry at an atmospheric temperature. When the cotton was almost dried then kept at $105^{\circ} \mathrm{C}$ for 3 hours in an oven for completely drying. Later the cotton was collected from oven and equilibrates with atmospheric conditions for 24 hours. These cotton samples were immersed into a series of volumetric flasks containing $10 \mathrm{~mL}$ of $0.1 \mathrm{M} \mathrm{HCl}$ aqueous solutions. After 30 minutes stirring, UV-Visible spectra from each of the sample solution were recorded.

\section{Interaction of $\mathrm{LC}$ and various cellulosic fibres}

A series of solutions containing $0.5,1.0,1.5,2.5$, and $3.5 \mathrm{mg} / \mathrm{mL}$ of $\mathrm{LC}$ were prepared using $0.1 \mathrm{M}$ $\mathrm{HCl}$ acid. Then $60 \mathrm{mg}$ cotton fibres was immersed into $50 \mathrm{~mL}$ solution with 15 minutes gentle 
shaking. Then the sample was conditioned and experiment was carried out as mentioned in case of saturation experiment. Similar technique was applied for jute and coir fibres.

\section{Kinetic studies}

Cotton fibres $(60 \mathrm{mg})$ was immersed into $50 \mathrm{~mL}$ of stock solution $(2.5 \mathrm{mg} / \mathrm{mL})$ and was stirred for 5 minutes. After conditioning the fibres as mentioned in saturation experiment, the fibres was put into $10 \mathrm{~mL} 0.1 \mathrm{M} \mathrm{HCl}$ and gently stirred upto 50 minutes. UV-Visible spectra were recorded after $5,10,15,20,30,40,50$ minutes. Similar experiment was carried out only addition of potato starch so that the solution contains $2 \%$ starch $\mathrm{w} / \mathrm{w}$ keeping unchanged the remaining parameters.

\section{Reference standard solution of Lidocaine Hydrochloride}

After investigating the solubility of $\mathrm{LC}$ in distilled water having $\mathrm{pH}$ about 6 and in $0.1 \mathrm{M} \mathrm{HCl}$ aqueous solution, a reference standard curve for UV-Vis absorbance vs concentration was drawn as shown in Fig. 1. The absorbances recorded from the concentrations between 5 and $30 \mu \mathrm{g} / \mathrm{mL}$ with the five units increment. The line shows a root means square value of 0.999 , which also indicates the preciseness and accuracy of data obtained from absorbance. It is revealed that with increasing concentration of $\mathrm{LC}$ in $0.1 \mathrm{M} \mathrm{HCl}$ acid, the absorbance goes upward with the concordance of constant rate. This graph has been used to find out the quantity of drug actually adsorbed or desorbed.

\section{Characterization}

UV-Vis spectroscopy measurements: The absorbance of LC was estimated by UV-Vis spectroscopy measurements using a UV-Vis spectrophotometer (double beam, wavelength range 190-1100 nm, Shimadzu UV-1700 Spectrophotometer, accuracy: \pm 0.002 , repeatability: \pm 0.001 , Japan, fitted with one centimeter matching quartz cell.

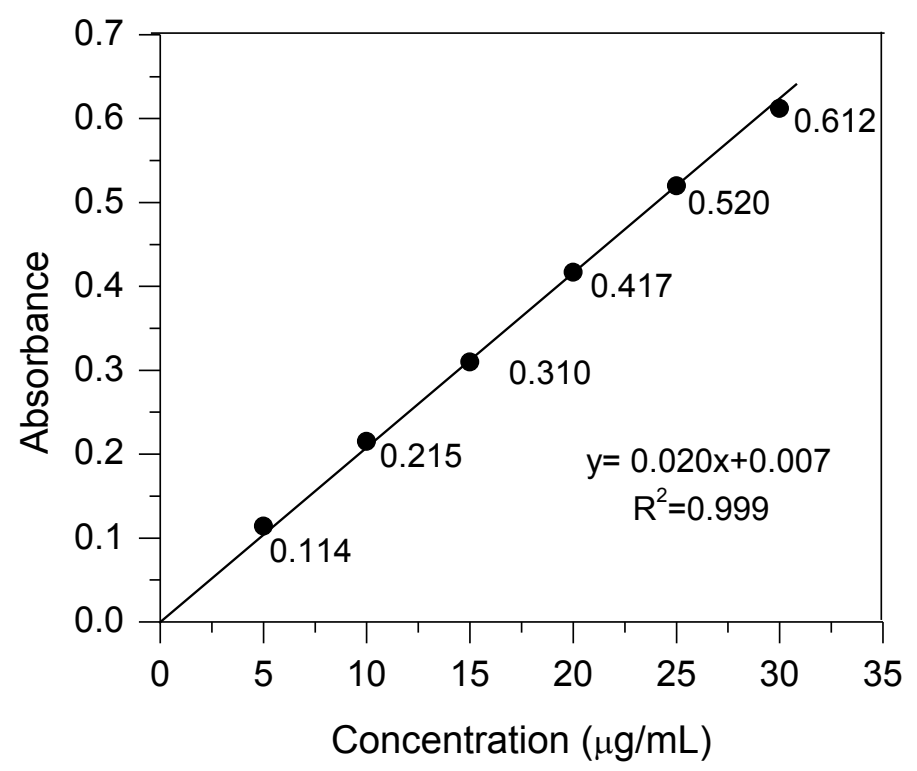

Figure 1. Standardization of Lidocaine hydrochloride drug in $0.1 \mathrm{M} \mathrm{HCl}$ aqueous solution using UV-Vis spectra at $262 \mathrm{~nm}$.

\section{Results and discussion}

To study interaction phenomena between cellulosic fibres, and LC (Fig. 2), three different natural fibres (c.f. cotton, jute and coir fibres) were chosen. Natural fibres show identical physicochemical properties due to its continuity, flexibility, fibre length, fineness, strength and other adhering chemicals [10]. A continuous natural filament consists of crystalline and amorphous segments, where adsorption occurs mainly onto the surface of soft amorphous regions due to its susceptibility of ionization in aqueous systems and polarity effect. Among these fibres, cottons are mainly used for bandage and as a filler to prevent breaking of Tablet in a container in pharmaceutical industries. 
Therefore, our attempt was set for an extensive investigation of interaction phenomena between LC and cotton fibres. Here, we have discussed interactions in terms of adsorption and desorption, kinetic studies and effect of binder separately.

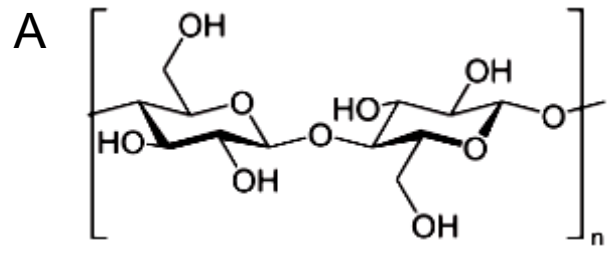<smiles>[B]c1cccc(C)c1NC(=O)CN(CC)CC</smiles>

Figure 2. Schematic formulation of cellulosic fibres (A) and Lidocaine (B)

\section{Surface saturation of cotton fibres with LC}

Cotton surface saturation with LC was investigated using $2.5 \mathrm{mg} / \mathrm{mL}$ aqueous solutions of LC when volume of solution $(50 \mathrm{~mL})$ and weight of cotton $(60 \mathrm{mg})$ were remained unchanged. It is noteworthy to mention that before investigation of self-assembled adsorption and saturation phenomenon, the solubility of LC was checked. The solubility of LC in distilled water ( $\mathrm{pH}$ of water is usually below 7) is not good. The limited solubility indicates that the appreciable acid $(\mathrm{pH}<7)$ could not produce enough protons to increase the solubility of LC. In UV-Vis spectroscopy analysis, it is revealed that when the concentrations of LC in distilled water and in $0.1 \mathrm{M} \mathrm{HCl}$ aqueous solution were equal, the absorbance recorded from the solution of distilled water was almost half of the absorbance obtained from acid solution. That means, the LC in distilled water was apparently soluble, but in $0.1 \mathrm{M} \mathrm{HCl}$ the LC drug was freely dissolved in molecular level and no aggregation was formed, as a result the enhanced absorbance was found. Therefore, in all experiments, aqueous solution of $0.1 \mathrm{M} \mathrm{HCl}$ was used.

Fig. 3 shows the adsorption of LC onto the surface of cotton fibres in $0.1 \mathrm{M} \mathrm{HCl}$ acid medium. LC has tert- amine functional group which is insoluble in alkali media, because of lone-pair of electron presence in nitrogen atom which is negatively influenced to become insoluble suspended LC. In acid media, protonated amine is produced and increased the solubility in aqueous system. On the other hand, the enthalpy of adsorption depends on the extent of surface coverage, mainly because the adsorbate particles interact. If the particles repel each other the enthalpy of adsorption becomes less exothermic as coverage increases. If the adsorbate particles attract each other then they tend to cluster together in islands and growth occurs at borders. These adsorbates also show order-disorder transitions when they are heated enough for thermal motion to overcome the particleparticle interactions but not so much that they are desorbed [21].

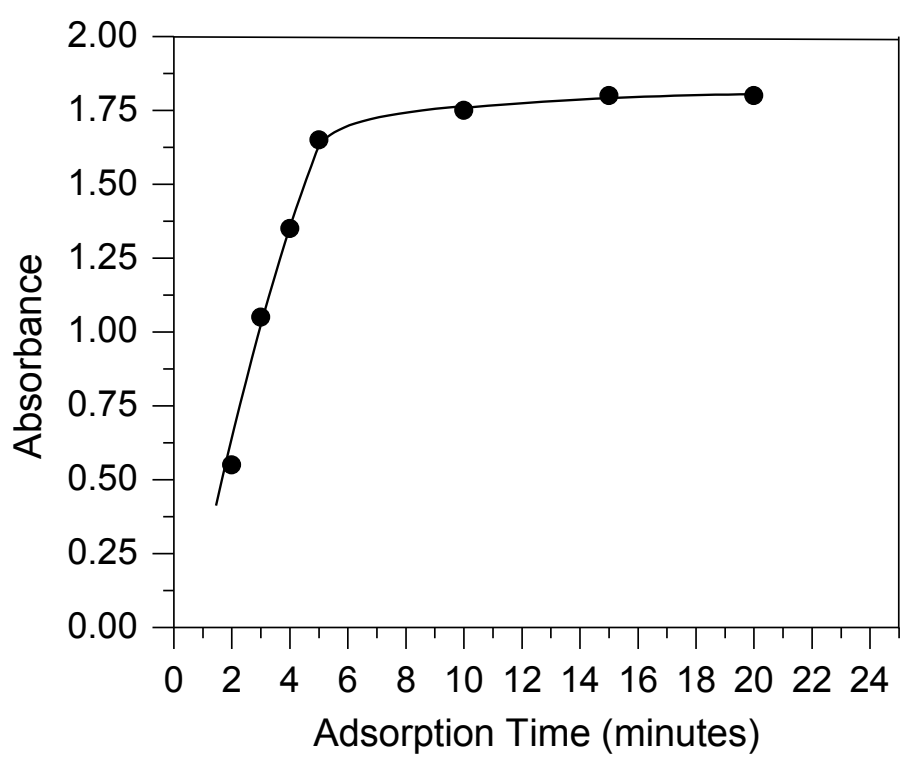

Figure 3. Saturation curve shows UV-Vis absorbance with respect to time (min) when $60 \mathrm{mg}$ cotton was immersed in $2.5 \mathrm{mg} / \mathrm{mL}$ Lidocaine hydrochloride 
Fig. 3 shows an adsorption onto $60 \mathrm{mg}$ cotton in presence of $50 \mathrm{~mL} \mathrm{LC}(2.5 \mathrm{mg} / \mathrm{mL})$ aqueous $0.1 \mathrm{M} \mathrm{HCl}$ solution upto 20 minutes. UV-Vis spectrum was recorded after 30 minutes of gentle shaking into $10 \mathrm{~mL}$ of $0.1 \mathrm{M} \mathrm{HCl}$. It was expected that after 30 minutes of shaking, almost all of the LC were released from substrate, which has been discussed later during kinetic studies. The graph indicates that the absorbance increases linearly with the increase of interaction time. The trend line is quite steady till 5 minutes which indicates that the initial rate of adsorption was also linear at which rapid interaction occurred and LC accumulation onto the cotton surface reached at a critical value. After 5 minutes, the small absorbance gradient proved the slow adsorption rate and reached an equilibrium concentration at which the adsorption and desorption rate is equal.

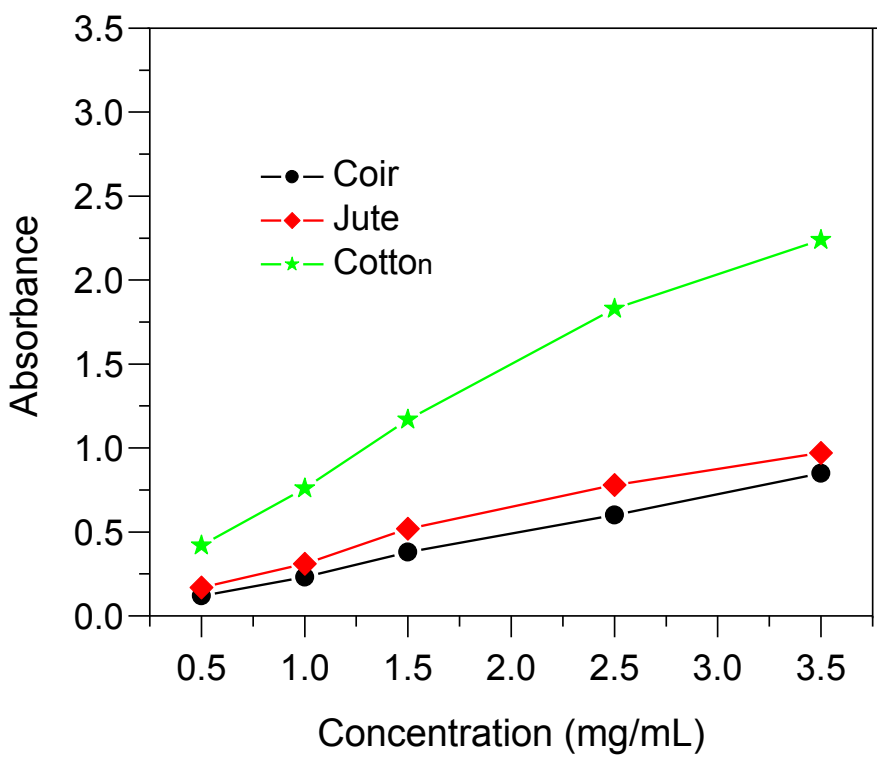

Figure 4. Effect of concentration of LC on loading capacity of cotton, jute and coir fibres.

In Fig. 4, absorbance vs concentration graph shows adsorption capacity of various natural fibres, cotton, jute and coir. Since the cotton fibres saturation with LC was reached within short time, these experiments were conducted 15 minutes for adsorption and 30 minutes for desorption. Coir showed the lowest absorbance (from 0.12 to 0.85 ), compared to the absorbances obtained from other fibres with all over the concentration ranges from 0.5 to $3.5 \mathrm{mg} / \mathrm{mL}$. The lowest value of absorbance in case of coir could be explain that the agglomeration of coir fibres which prevent the inflow of LC into core of coir moieties. In addition to prevention of adsorption, adsorbed LC could not release into bulk of solution from capillary of coir beads. The overall absorbances from jute fibres were found very close to the absorbances obtained from coir. Jute is a continuous fibres having strong structure, waxy additives, higher percentage of lignin content. The surface area of jute per unit weight relative to cotton is low, as a result the interaction between LC and jute fibres is low, giving to lower adsorption capacity. Finally, low LC containing jute desorbs few drugs into solvent and results a low absorption.

Absorption for cotton fibres from $0.5 \mathrm{mg} / \mathrm{mL}$ solution was recorded 0.4 which is more than twice of the absorbance of coir and jute. As the concentration increased, the absorbance was also increased linearly following the same pattern of coir and jute with the higher values of absorbances. At $3.5 \mathrm{mg} / \mathrm{mL}$ solution, the highest absorbance was recorded for cotton fibres which is equivalent loading to $18 \mathrm{mg} / \mathrm{g}$ of cotton. It is noteworthy to mention that one part of cotton of a cotton bud (12 mg) which may contain $0.22 \mathrm{mg}$ of LC drug.

Furthermore, there are several factors which will affect the extent of adsorption from solution [22]. These are including solute concentration, temperature, value of $\mathrm{pH}$ and surface area of adsorbent. When drug concentration increases, it will cause an increase in the amount of adsorption that occurs at equilibrium until a limiting value is reached. Adsorption is generally exothermic and hence an increase in temperature leads to decrease in adsorption. The influence of $\mathrm{pH}$ is usually 
through a change in the ionization of the solute and the influence will be depending on which species is more strongly adsorbed. An increased surface area achieved by a reduction in particle size or the use of a porous material will increase the extent of adsorption.

\section{Influence of surface area of cotton fibres}

Cotton fibres are practically very thin and light. It has some unique properties comparative to other natural fibres like jute and coir. The Fig. 5 shows that as the weight of cotton increases, the absorbance of the desorbed LC increases linearly. Initially, $12 \mathrm{mg}$ of cotton was considered for the experiment because one head of cotton bud contains the same weight of cotton. Then the weight of cotton was increased with double, triple and multifold. The measured quantity of cotton was soaked into $50 \mathrm{~mL}$ of $2.5 \mathrm{mg} \mathrm{LC} / \mathrm{mL}$ acidic solution for 5 minutes. The overall absorbances for all respective weight for 10 minutes desorption showed higher values than the absorbances recorded for 5 minutes desorption. It is revealed that $12 \mathrm{mg}$ cotton released $198 \mu \mathrm{g} \mathrm{LC}$ after 5 minutes of shaking during desorption, whereas, $235 \mu \mathrm{g}$ was obtained after 10 minutes. Since, the adsorption time was constant but desorption was carried out for 5 and 10 minutes, the cotton almost released all LC, very few molecules were retained after 5 minutes.

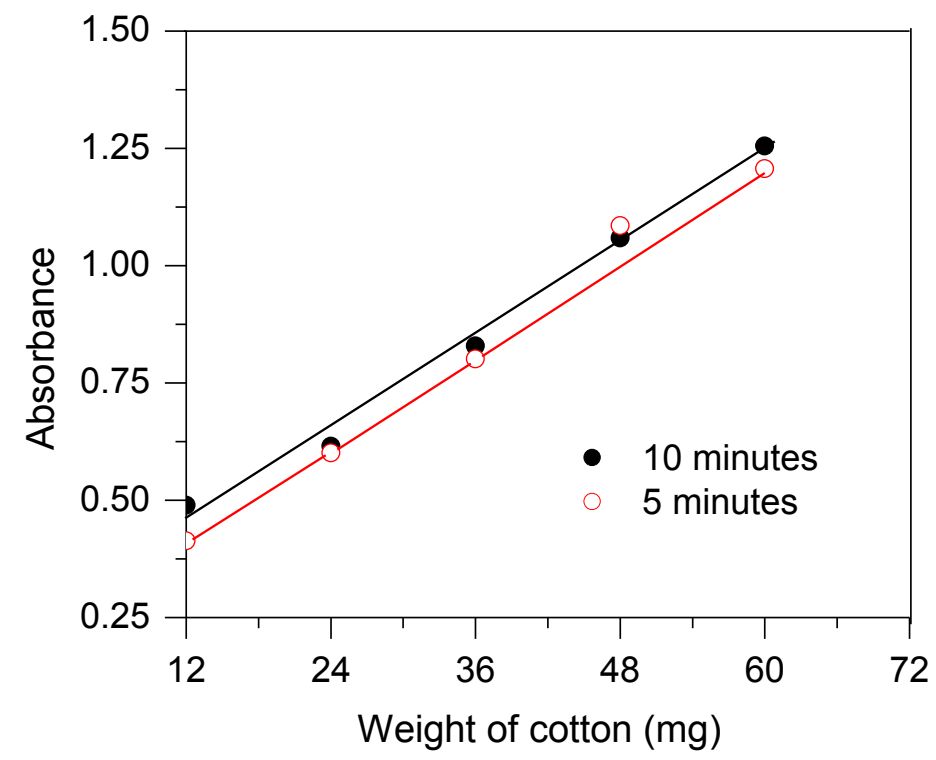

Figure 5. The curves for the UV-Vis absorbance with respect to weight of cotton fibres after 5 and 10 minutes desorption. 
The UV-Vis spectra for different weight $12,24,36,48$ and $60 \mathrm{mg}$ cotton are represented as A, B, C, $\mathrm{D}$ and $\mathrm{E}$ respectively in Fig. 6. The values of absorbance recorded from maxima at $262 \mathrm{~nm}$ are presented in the bottom right of the Fig. 6.
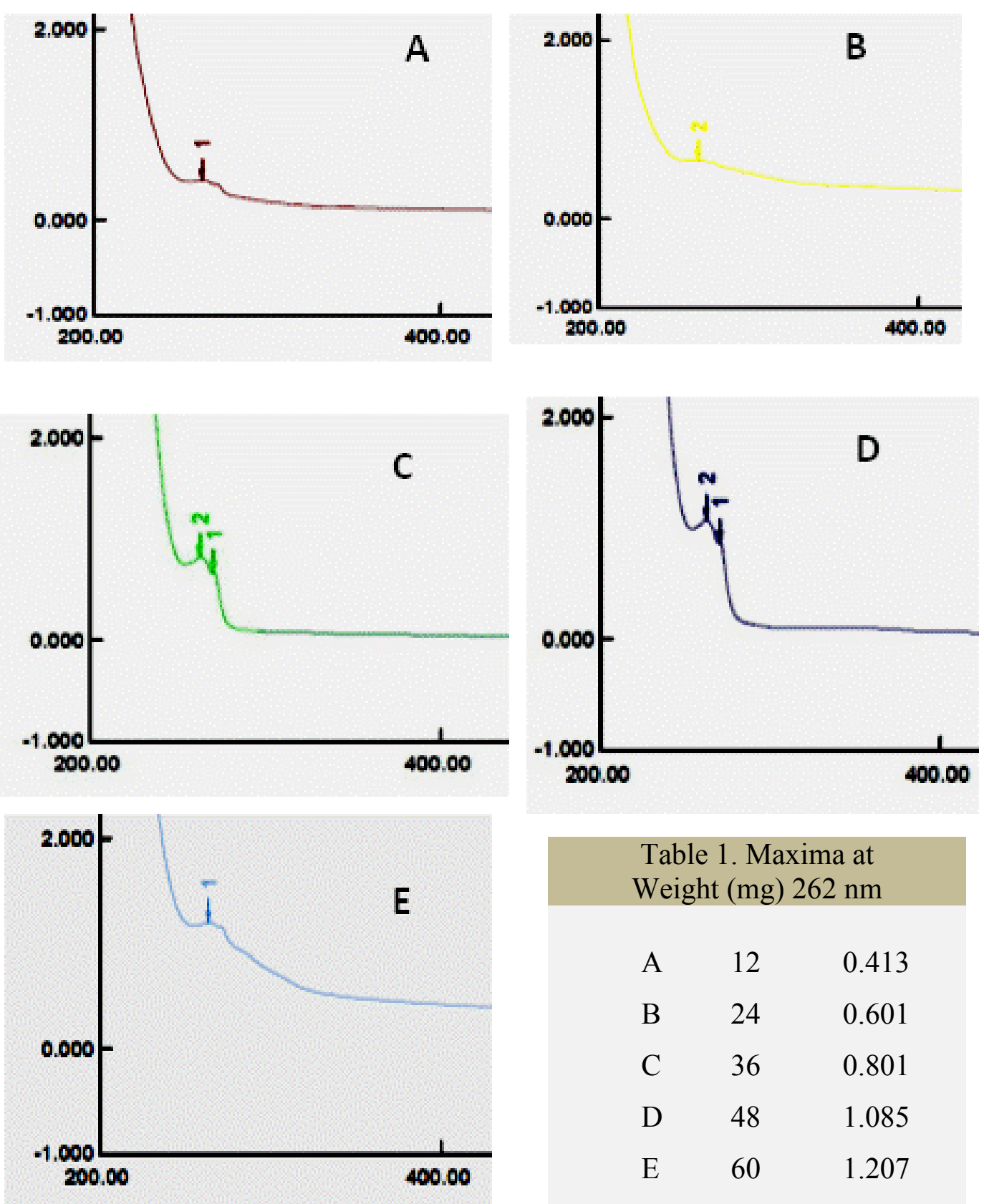

Figure 6. UV-Vis spectrum of LC recorded from different weight of cotton. (Adsorption time: 5 minutes and desorption time: 5 minutes)

\section{Kinetic studies}

Fig. 7(A) shows the effect of time on desorption of $\mathrm{LC}$ in $0.1 \mathrm{M} \mathrm{HCl}$ aqueous solution. It can be seen from Fig. 7(A) and Fig. 8 that desorption of LC increased rapidly with a regression $\mathrm{R}^{2}=0.9987$ upto $30 \mathrm{~min}$. and then increased very little therefore no further remarkable desorption occurred after $30 \mathrm{~min}$. At this stage, the solution obtained from $60 \mathrm{mg}$ cotton after 5 minutes of immersion into $2.5 \mathrm{mg} / \mathrm{mL}$ LC drug showed absorbance 1.655 which indicates the equivalent of $82 \mu \mathrm{g} / \mathrm{mL}$ LC concentrations. The linear and steady release of drug indicates about the adsorption pattern onto the surface of cotton. Since the rate is not unsteady, one can easily understand that 
there was no excessive adsorbed LC drug other than self-assembled monolayer which is directly adsorbed on the cotton surface. Another investigation was carried out where, LC drug concentration, cotton weight, adsorption time were constant but additionally potato starch $(2 \% \mathrm{w} / \mathrm{w}$ in $0.1 \mathrm{M} \mathrm{HCl}$ ) was added as an adhesive so that the drug can adhere with cotton.
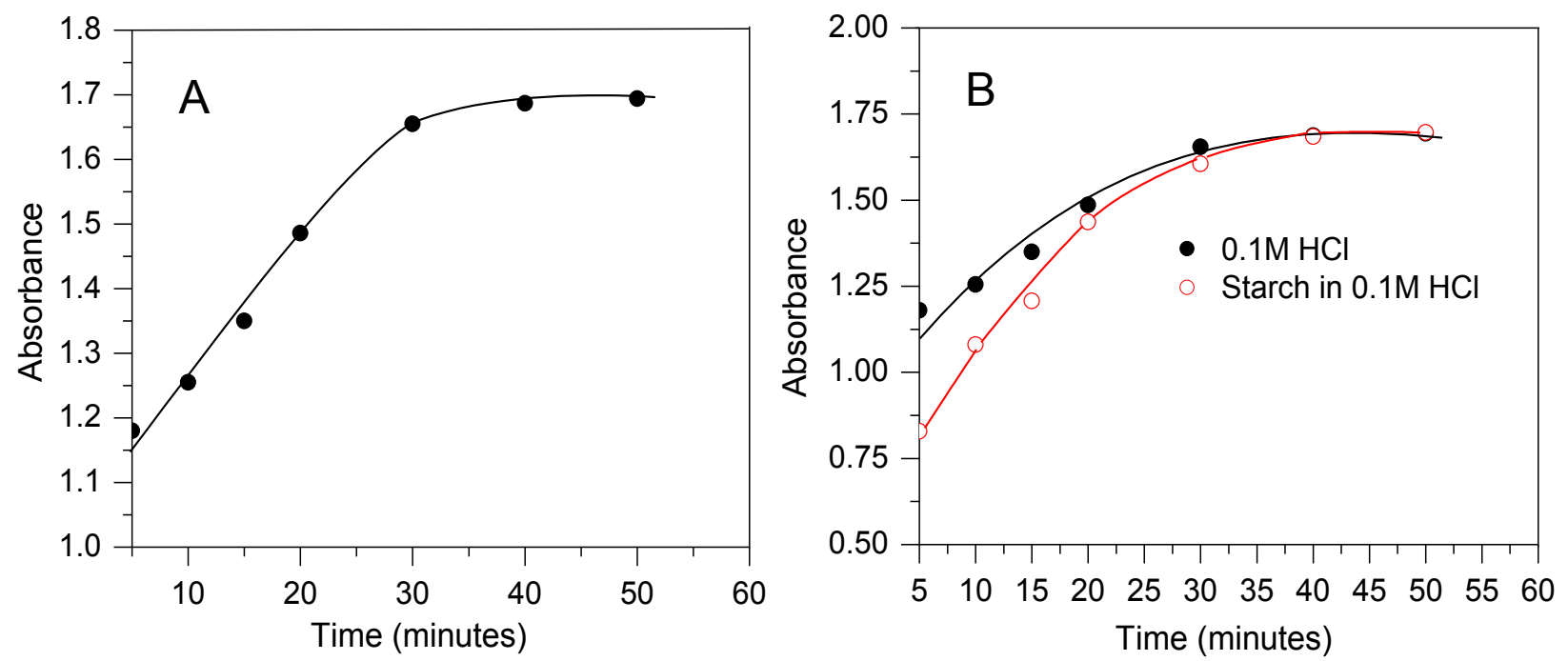

Figure 7. Rate of desorption of LC into $0.1 \mathrm{M} \mathrm{HCl}$ from $60 \mathrm{mg}$ cotton after saturation with $2.5 \mathrm{mg} / \mathrm{mL}$ for 5 minutes (A) and a comparison studies in terms of with $(2 \% \mathrm{w} / \mathrm{w})$ and without starch (B)
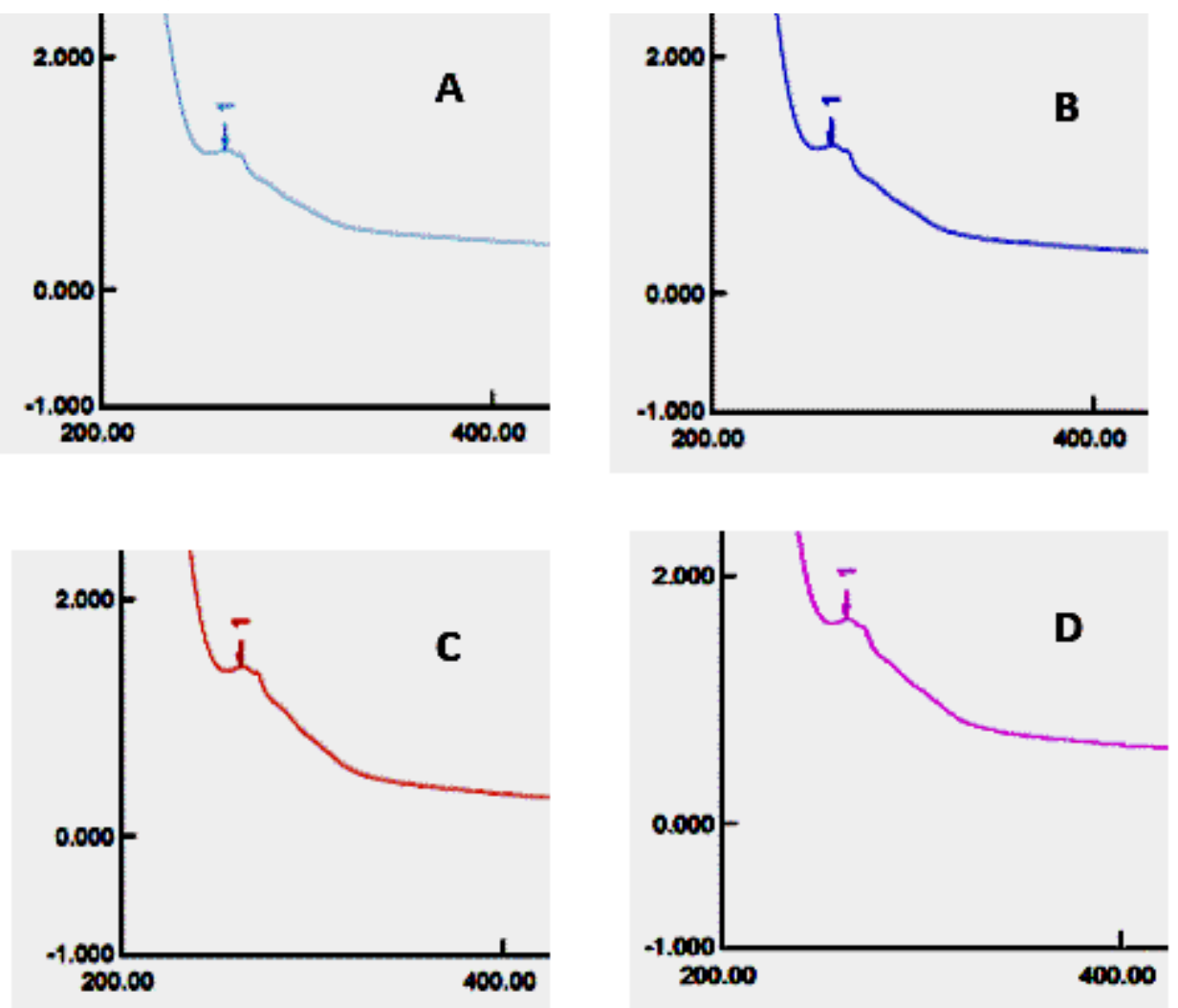

Figure 8. UV-Vis Spectra A, B, C and D recorded after 5, 10, 20, 30 minutes respectively when kinetic of desorption was studied.

UV-Vis spectra in presence of starch are not shown. The Fig.7 (B) shows that when starch was used then after five minutes, the absorbance found was lower than the absorbance recorded from without starch solution. Table 1 represents all the values of absorbances and corresponding concentration of drug during kinetic of desorption was studied. 
Table 1: The Table represents absorbance, concentration of drug as well as the total quantity of drug released in aqueous solution after 5, 10, 15, 20, 30, 40, 50 minutes.

\begin{tabular}{c|c|c|c}
\hline Time (min) & Absorbance & Conc. $(\boldsymbol{\mu g} / \mathbf{m L})$ & Drug weight $(\mathbf{m g})$ \\
\hline 5 & 1.18 & 59 & 0.59 \\
10 & 1.255 & 62 & 0.62 \\
15 & 1.35 & 67 & 0.67 \\
20 & 1.486 & 74 & 0.74 \\
30 & 1.655 & 82 & 0.82 \\
40 & 1.687 & 83 & 0.83 \\
50 & 1.694 & 84 & 0.84 \\
\hline
\end{tabular}

\section{Possible mechanism of adsorption of $L C$ on cotton fibres}

The typical adsorption isotherm of LC on cotton fibers is shown in Fig. 4 (Abs vs Conc.). This isotherm of type Langmuir type is generally associated with monolayer adsorption. ${ }^{33}$ However, their initial slopes do not lie very close to the $y$-axis.

This either shows that the affinity of LC for the cotton fibers is moderate or, on the other hand, that this affinity may be ascribed to a Van der Waals force. The Langmuir isotherm shows that the amount of LC adsorbed increases as the concentration increases up to a saturation point. Beyond this point, increasing the LC concentration will not cause further increase. This behavior is typical of fibers with a limited number of accessible sites. As long as there are available sites, adsorption will increase with increasing LC concentration, but as soon as all of the sites are occupied, a further increase in concentration will not increase the amount of LC on fibers. In the case of cotton fiber, we observed that the equilibrium concentration of LC is more than 0.015 gmol $\mathrm{L}^{-1}$. This may be due to desorption of the drug molecule at above the mentioned concentration. The concentration of cotton fibres would be possible to calculate $0.0085 \mathrm{~g}$ unit $\mathrm{mol} / \mathrm{L}$ by considering the unit molecular weight of glucose unit. When $2.5 \mathrm{mg} / \mathrm{mL}(0.0108 \mathrm{~g} \mathrm{~mol} / \mathrm{L}) \mathrm{LC}$ drug solution was prepared then the ratio between glucose unit and LC drug was found 1.27. After 30 minutes of adsorption into $2.5 \mathrm{mg} / \mathrm{mL}$ solution and desorption of drug into $10 \mathrm{~mL}$ of solution using $60 \mathrm{mg}$ of cotton, the absorbance was recorded 1.66 that means the amount of drug $0.82 \mathrm{mg}$ was interacted. The obtained concentration of LC drug was $82 \mu \mathrm{g} / \mathrm{mL}$, i.e. $0.00035 \mathrm{~g} \mathrm{~mol} / \mathrm{L}$. The cotton was adsorbed about $3.27 \%(\mathrm{~mol} / \mathrm{mol})$ LC from the stock solution and about 24 unit mol of cotton captured only a single LC molecule.

A schematic of the interaction between the LC molecule and cotton fiber surface is shown in Fig. 9. We assume that there is a complete adsorption of LC as a monolayer onto the surface of cotton fibers as shown by the plateau of the adsorption isotherm.
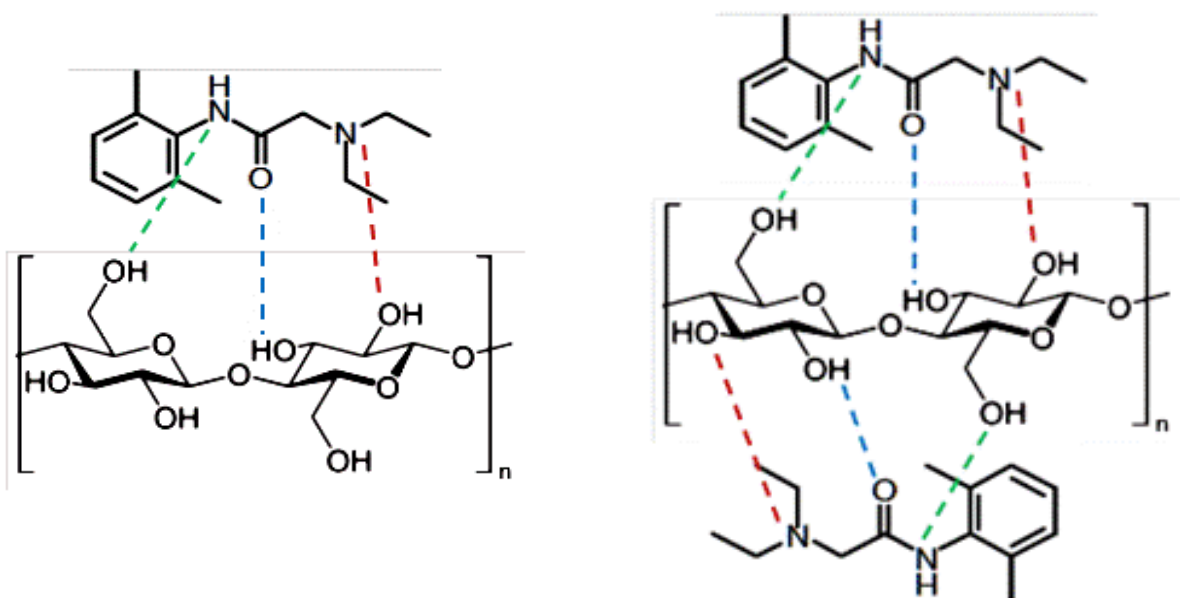

Figure 9. Possible interacting site of LC and cotton fibres. (left: $50 \%$ saturation and right: $100 \%$ saturation)) 
The capacity of adsorption depends on several parameters such as the specific surface area, the expansible character, the mobility of LC drug molecules in the liquid phase and in the interior of the substrate, and the forces of attraction between the surface of substrate and the molecules of LC $[23,24]$. The coulombic forces between LC drug species and negatively charged cellulose in water are the major interactions which affect the adsorption of LC drug on the cellulose. The shapes of LC drug adsorption isotherm was found to coincide with the S-type isotherm reported by Giles et al. [25]. The isotherm S-shaped, probably corresponds to electrostatic adsorption of one layer, followed by adsorption of second layer by van der waals attraction. The S-type isotherm depends upon the Freundlich assumption about the heterogeneity of the surface. The presence of various planes, as fibers leads to heterogeneous adsorption behavior [25].

\section{Conclusion}

Adsorption and desorption of Lidocaine onto cotton, jute and coir fibres have been investigated in terms of drug concentration, weight of fibres, time of adsorption. It is revealed that cotton has the highest capacity for adsorption among the fibres used. Since Lidocaine has only one active site (tert- amine) for polarization, a weak interaction between hydroxyl of cotton and Lidocaine occurred. Due to a monolayer formation, a constant release rate of Lidocaine drug was observed. After 30 minutes of adsorption into $2.5 \mathrm{mg} / \mathrm{mL}$ solution and desorption of drug into $10 \mathrm{~mL}$ of $0.1 \mathrm{M}$ $\mathrm{HCl}$ solution and $82 \mu \mathrm{g} / \mathrm{mL}$, i.e. $0.00035 \mathrm{~g}$ mol Lidocaine /L was recovered from $60 \mathrm{mg}$ of cotton. The cotton was adsorbed about 3.27\% (mol/mol) Lidocaine from the stock solution and about 24 unit mol of cotton captured only a single Lidocaine molecule. In the presence of potato starch, the release of Lidocaine drug was slow down and a delayed release pattern was observed. It is crucially important that one would formulate advanced formulation with adjusting the drug amount on cotton surface for medication of tooth gum pain as a local anesthesia.

\section{Acknowledgement}

The authors are grateful to Bangladesh University Grant Commission for financial support to carry out this research work. The authors are also grateful to Mr. Dipok Kumar Sharma for his kind help throughout this work done.

\section{References}

[1] S. Perez, D. Samain, Structure and engineering of celluloses, Adv. Carbohydr, Chem. Biochem. 64 (2010) 5-116.

[2] M. Z. Rong et al., The effect of fiber treatment on the mechanical properties of unidirection sisal-reinforced epoxy composites, Compos. Sci. Technol. 61 (2001) 1437-1447.

[3] E. I. Filpponen, The synthetic strategies for unique properties in cellulose nanocrystal materials, PhD Thesis, 2009; North Carolina State University, Page 1. URI: http:/www.lib.ncsu.edu/resolver/ $1840.16 / 4626$.

[4] D. Wandera, S. R. Wickramasinghe, S. M. Husson, Stimuli-responsive membranes, J. Membr. Sci. 357 (2010) 6-35.

[5] Y. Nishio, Material functionalization of cellulose and related polysaccharides via diverse microcompositions, Adv. Polym. Sci. 205 (2006) 97-151.

[6] A. Carlmark, E. E. Malmstrom, ATRP Grafting from Cellulose Fibers to Create BlockCopolymer Grafts, Biomacromol. 4 (2003) 1740-1745.

[7] B. Biswal, J. Anurekha, Drug-excipient Interaction Study for Apple Cider Vinegar with 20 Potential Excipients using Modern Analytical Techniques, Asian J. Pharma. 10(1) (2016) 65-71.

[8] P. Crowley, L. G. Martini, Drug-Excipient Interaction. Pharmaceutical Technology Europe, Advanstar. (2001) 0582.

[9] S. A. Muratova et al., Studying interactions in microcrystalline-drug systems, Pharm. Chem. J. 36 (2002) 619-621. 
[10] R. Fangueiro, S. Rana, Natural Fibres: Advances in Science and Technology Towards Industrial Applications, (Edited) Springer, 2016.

[11] R. Kolakovic et al., Evaluation of drug interactions with nanofibrillar cellulose, Eur J Pharm Biopharm. 85 (2013) 1238-44.

[12] N. D. Burkhanova et al., Interaction of drugs with microcrystalline cellulose at the molecular and supramolecular levels. Chem. Nat. Comp. 33(3) (1997) 440-446.

[13] S. Al-Nimry, S. Assaf, I. Jalal, N. Najib, Adsorption of ketotifen onto some pharmaceutical excipients, Int. J. Pharm. 149 (1997) 115-121.

[14] M.S. El-Samaligy, G.M. El-Mahrouk. T.A. El-Kirsh, Adsorption-desorption effect of microcrystalline cellulose on ampicillin and amoxicillin, Int. J. Pharm. 31 (1986) 137-144.

[15] R.M. Franz, G.E. Peck, In vitro adsorption -desorption of fluphenazine dihydrochloride and promehazine hydrochloride by microcrystalline cellulose, J. Pharm. Sci. 71 (1982) 1193-1199.

[16] D. N. T. Kumar et al., Purified and Bio-polished Cotton Fibers as DNA-Streptavidin Tags for Bio-applications, using a Novel Approach, Inter. J. Eng. Res. Appl. (2012) 1117-1123.

[17] A. Cavaco-Pauloa, J. Morgadoa, J. Andreausb, D. Kilburn, Interactions of cotton with CBD peptides, Enzy. Micro. Technol. 25 (1999) 639-643.

[18] A. R. Khan, H. Tahir, F. Uddin, U. Hameed, Adsorption of Methylene Blue from aqueous Solution on the Surface of Wool Fiber and Cotton Fiber, J. Appl. Sci. Environ. Mgt. 9(2) (2005) 29 -35 .

[19] C. Kaewprasit, E. Hequet, N. Abidi, J. P. Gourlot, Application of Methylene Blue Adsorption to Cotton Fiber Specific Surface Area Measurement: Part I. Methodology, J. Cott. Sci. 2 (1998) 164-173.

[20] S. Okada, H. Nakahara, H. Isaka, Adsorption of drugs on microcrystalline cellulose suspended in aqueous solutions, Chem. Pharm. Bull. 35 (1987) 761-768.

[21] P. W. Atkins, Physical chemistry, (5 ${ }^{\text {th }}$ Edition) Oxford university press, Oxford. (1994) pp. 986-993.

[22] M. E. Aulton, Pharmaceutics The science of dosage form design, Churchill Livingstone. London. (58-61) (2000) 616-628.

[23] M. Bagane, S. Guiza, Removal of a dye from textile effluents by adsorption, Ann. Chim. Sci. Mater. 25 (2000) 615-626.

[24] G. Rytwo, S. Nir, M. Crespin, L. Margulies, Adsorption and Interactions of Methyl Green with Montmorillonite and Sepiolite, J. Col. Inter. Sci. 222 (2000) 12-19.

[25] C. H. Giles, T. H. MacEwan, S. N. Nakhva, D. Smith, Studies in adsorption. Part XI. A system of classification of solution adsorption isotherms, and its use in diagnosis of adsorption mechanisms and in measurement of specific surface areas of solids, J. Chem. Soc. 56 (1960) 39733993. 